\title{
HUMAN RESOURCE AUTOMATION: BENEFITS AND CHALLENGES FOR ORGANIZATIONS
}

\author{
Rayyan Amour Al Noumani*, \\ Raihan Taqui Syedi
}

Faculty of Business \& Economics, Modern College of Business and Science,

Muscat, Oman

\begin{abstract}
:
Technological advancements have been reshaping the business world and automation in HR processes is becoming critical for organizations in general and Small \& Medium Enterprises (SMEs) in particular. HR automation not only enables them to stay connected with market needs, but also to enhance organizational effectiveness. Modern work environment is more physically disconnected than ever. Work relationships are becoming more flexible, fluid and fleeting which is affecting formulation and maintenance of long-term associations. Fast paced economic growth and technological advancements are forcing organizations to redesign themselves, so as to compete and succeed in today's global business environment. Few of these endeavors have facilitated better performance of various HR functions, but rest have posed challenges due to confusion and disruption. This article attempts to explore the scope of HR automation in SMEs by examining the benefits \& challenges and illustrating the way forward for enhanced organizational effectiveness.
\end{abstract}

Keywords:

Human Resource automation, SMEs.
Correspondence:

Rayyan Amour Al Noumani

e-mail:

rayyanamour97@gmail.com

\section{INTRODUCTION}

Technology today has emerged as the new architect of the modern work world and has changed the way HR departments in organizations function. With the technological processes ever evolving and substantial changes being experienced, HR professionals are expected to do more with less. It has become imperative for organizations to utilize these technological advancements appropriately in order to facilitate organizations to capitalize on their human capital. HR Automation will continue to play a viable role in overcoming the HR challenges of $21^{\text {st }}$ century. Technological upgrading has created a new generation of employees and has changed the fabrication of organizational structure. Managing workforce spread across various geographical locations, cultures, political systems has thrown up a daunting challenge for organizations.

HR Automation is not only about using new technological equipment, but also calls for re-skilling of employees and rewiring of organization culture. With the advent of globalization, rapid expansion of business and ever-demanding competitiveness, organizations today cannot rely on traditional methods of performing tasks. Absence of HR automation can have a crippling impact on modern workplace. Thus, there is a need to redefine the way organizations carry out HR functions to compete and attain success in the volatile business environment.

Rapid technological development has redefined the role of HR professionals and new roles have emerged which did not exist before. 
HR automation is one such panacea, increasingly helping eliminate inefficiencies and barriers to HR operations by facilitating enterprise wide integration and enhanced overall performance, speed and efficiency - thereby adding value to businesses.

The digital transformation and atomization workforce and workflow management will lead the business to be on the path of success and advancement. Moreover, the atomized system will lead to enhanced productivity, efficient strategizing and effective organizational culture. HR feature with the HR function is the chance to build new ways to contribute to organizational effectiveness through means such as knowledge management and the development of intellectual and social capital. Nevertheless, in its adoption of Information System (IS) Information Technology (IT) technologies, HR has lagged behind other internal functions. This article tries to explore the scope of HR automation in SMEs by examining the benefits \& challenges and proposing the way forward for enhanced organizational effectiveness.

\section{IMPACT OF HR AUTOMATION IN ORGANIZATIONS}

HR function is no longer considered as an administrative activity but has become strategic partner. This has resulted in transitioning of HR professional's role to that of a facilitator rather than implementer. Altarawneh (2010) argues that the emergence of Strategic HRM (SHRM) approach has created a real need for information about HR. Most of the studies show that HR automation helps in achieving primarily four objectives i.e. reduced time spent on administrative work, overall cost reduction, enhanced self-services and increased morale. According to Altarawneh and Al-Shqairat (2010), Ball (2001), Ngai and Wat (2006), Ruel et al., (2004), HR automation streamlines the administrative process, reduces the errors and deletes the repetitions, thereby increasing the task efficiency. Moreover, Information Technology (IT) revolution coupled with changes in social environment during the past decades have resulted in a global competitive market.

Figure 1. Year-over-Year comparison of factors correlated to organizational outcomes

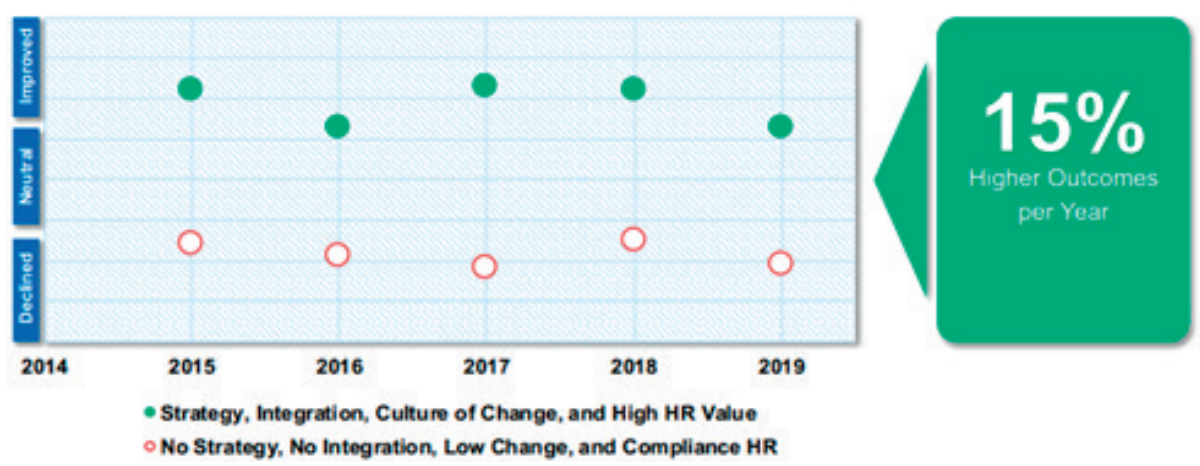

Source: 2019-2020 Sierra-Cedar HR Systems Survey

According to (Greif, Kühnis \& Warnking, 2016), it was found that the success between the company and its positivity is connected with the size of the company and its age; younger the company more successful the company will be in terms of advancement and functioning with technologies in HR. In addition, digital transformation can be the reason of creating multitude opportunities especially for SMEs as it will lead them to the path of success.
HR automation is a tool to digitalize the tedious and time-consuming functions and streamline all the functions of HR in order to increase the efficiency and have the ability to reduce the human errors. 


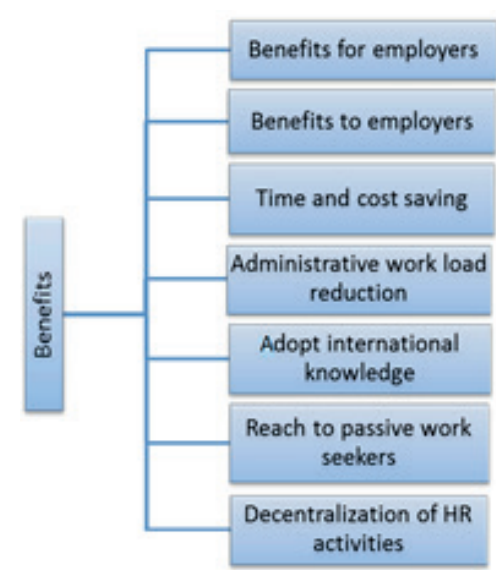

HR automation facilitates in reducing time spent on administrative work, increases both productivity and profitability due to the faster processing times, information sharing and access to data. Also, it reduces the administrative burden, provides instant access to information. Document driven process to get work done, without sacrificing the quality of work done and thereby it, enhances the efficiency of organization. Moreover, it reduces hiring cycle times by providing access to the large number of qualifying candidates through online, and also reduces recruitment cost. It also facilitates employee retention by enhancing transparency within the organization by providing access to the previous information about organizations and employees. Furthermore, it facilitates expansion of organization by providing quick worldwide access to the information needed and also supports information sharing thereby it facilitates organization to make important timely decisions about business. Finally, it reduces operation cost by promoting paperless environment and reducing the number of employees required to perform tasks manually by automating HR process.

\subsection{Benefits of HR Automation for Employees and Organizations}

HR automation enhances employee motivation since they will get more done in short period of time, there are less chances for committing errors, and it also eliminates recurring monotonous jobs. Furthermore, it facilitates employees in determining their career path, as HR automation provide access to information about performance appraisal reviews, and other important information about their job and company. Moreover, it improves employee communication by providing access to job related information with the timeliness and accuracy. The recruitment processes are being cut down because of the fast exchange of information, applications can be sent within seconds, mails are being directly sent to the recruiter email address.
According to Deillon (2014) this technology is saving cost and time of an applicant and recruiter, thus the cost of technology job posting normally is lower than printed media, head-hunter, and employment agencies and more of the other traditional recruitments. Since recruitment is being automated by integrating tools to system many of the tasks will be transformed from manual to atomized tasks that will be the reason of increasing the efficiency and decreasing the working load on the administrators. Online recruiting has brought in the new term of candidates to be able to reach to passive work seekers as (Deillon, 2014) stated in an example of students in USA in the year $2000,90 \%$ of students have been looking for jobs actively in the internet as it is showing it is a way of finding passive job seekers.

\subsection{Challenges faced by Organizations regarding HR automation}

Work world today is more disconnected than ever. Disruptive technologies have changed the way people work, communicate and collaborate. Organizations will have to deal with a scarcity of key talent, constantly shifting skill requirements, meeting the needs of different generation, on top of it, bringing everyone on the same page and working together is a big challenge for HR Today. Biggest challenge for the organization to consider is whether the technology adopted ensures no gap between the expected service and actual service rendered by the technology and is capable of analyzing needs of the organization and business readiness. It is also important that organization should decide on whether technology is built and managed on the inside or from outsource.

It is very important to assess whether the organization is ready to implement technological change at its current growth stage and ready to face the changes arising out of automation process.HR department is not known for early adoption and organization and can experience inertia. 
Employees may not feel comfortable in adopting the new methods of doing work with the fear of losing jobs, motivating employees to work with new technology is a big challenge. HR is more complicated part of business organization. It is experiencing flood of information. Employee information located in different formats and on different media, finding what you need when you need it is a constant challenge. Organizations, including SMEs, should be clear about what kind of information should be shared - who can have access to data and who will be authorized to change information; otherwise it would result in security and privacy issues. Another biggest challenge while automating HR is to make sure that everyone in the organization stick to the company confidentiality and code of ethics, policies, employees should understand the fact that they should not disclose their passwords or compromise organization security in anyway.

\section{CONCLUSION}

The review of literature on HR automation and SMEs highlight $\mathrm{HR}$ automation is actually efficient and there are more benefits compared to the challenges. Many countries acknowledge the importance of adopting new technologies within SMEs and are encouraging the adoption of the HR systems for better outcome and achievements. Thus, SMEs and start-ups around the world are trying to replace traditional HR practices with automated processes. HR Automation and adopting new technologies within HR management in SMEs would definitely benefit SMEs in long run, result in enhanced efficiency and will lead to further advancement of processes.

\section{LITERATURE}

Altarawneh I \& Al-Shqairat, Z. (2010). Human Resource Information Systems in Jordanian Universities. International Journal of Business and Management, 5(10), 113- 127

Ball, Kirstie S. (2001). The Use of Human Resource Information Systems: A Survey. Personnel Review, 30(6), 667-693

Broderick, R., \& Boudreau, J. W. (1992). Human resource management, information technology, and the competitive edge. Academy of Management Perspectives, 6(2), 7-17

Chakraborty, A. R., \& Mansor, N. N. (2013). Adoption of Human Resource Information System: A Theoretical Analysis. Procedia - Social and Behavioral Sciences, 75, 473-478

Chen, Y., Jaw, Y., \& Wu, B. (2016, February 01). Effect of digital transformation on organizational performance of SMEs: Evidence from the Taiwanese textile industry's web portal.

Deillon, C. (2016). The advantages and challenges of turning towards e-recruitment for small and medium sized businesses (SME). University of Fribourg
Harris, S \& Amy L. (2020). The Sierra-Cedar 2019-2020 HR Systems Survey White Paper $22^{\text {nd }}$ Annual Edition

Ikhlas Altarawneh Zaid Al-Shqairat (2010). Human Resource Information Systems in Jordanian Universities International Journal of Business and Management Vol 5, No 10

Julie Bulmash (2006). Human resource management and technology/ catalogue.pearsoned.co.uk

Gardner, S., Lepak, D., \& Bartol, K., (2003). Journal of Vocational Behavior

Kenneth A. Kovach, Allen A. Hughes, Paul Fagan, \& Patrick G (2002). Administrative and Strategic Advantages of HRIS (www.interscience.wiley.com)

M Nishad Nawaz \& Anjali Mary Gomes (2014). Automation of the HR functions enhance the professional efficiency of the HR Professionals-A Review IJMIE Volume 4, Issue 2

Machado, C., \& Davim, J. P. (2016). Technological challenges and management: Matching human and business needs. Boca Raton: CRC Press, Taylor \& Francis Group

Myra Bari (2016). Should Business Automate HR Functions?

Ngai, E. W. T., Law, C. C. H., \& Wat, F. K. T. (2008). Importance of the Internet to Human Resource Practitioners in Hong Kong. Personnel Review, 37(1), 66-84

Poorangi, M. (2011). SMEs Portfolio of e-Recruitment: Malaysian Perspective. International Journal of E-Education, E-Business, E-Management and E-Learning

Ruël, H.J.M., Bondarouk, T.V., \& Looise, J.C. (2004). E-HRM: innovation or irritation? An exploration of web-based human resource management in five large companies. Management Revue, 15, 3

Scupola, A., \& Pollich, Z. (2019). Adoption of Human Resource Information Systems in Danish SMEs. In Conference Proceedings

Shilpa, V., \& Gopal R. (2011). The Implications of Implementing Electronic- Human Resource Management (E-HRM) Systems in Companies. Journal of Information Systems and Communication, Vol. 2, Issue 1, 2011, pp-10-29

Singh, R. K., Garg, S. K., \& Deshmukh, S. (2009). The competitiveness of SMEs in a globalized economy. Management Research Review, 33(1), 54-65

Thomas, G. (2020). Digital Maturity of HR in SMEs 